\title{
The influence of stretch wrap containment force on load bridging in unit loads
}

\author{
Jonghun Park ${ }^{1}$ (D) । Laszlo Horvath ${ }^{2}$ (D) | Marshall White ${ }^{2}$ (D) | Philip Araman ${ }^{3}$ । \\ Robert J. Bush ${ }^{2}$ (D)
}

${ }^{1}$ School of Graphic Communications

Management, Ryerson University, Toronto, ON M5B2K3, Canada

${ }^{2}$ Department of Sustainable Biomaterials, Virginia Tech, Blacksburg, VA 24061, USA

${ }^{3}$ Southern Research Station, USDA Forest Service, Blacksburg, VA 24061, USA

\section{Correspondence}

Laszlo Horvath, Department of Sustainable Biomaterials, Virginia Tech, Blacksburg, VA 24061, USA.

Email: Ihorvat@vt.edu

\section{Funding information}

US Department of Agriculture (USDA) Forest Service, Grant/Award Number: 14-JV-

$11330142-070$
The term "load bridging" describes a phenomenon in which the physical interaction between various packaging components acts as a series of discrete loads in a given unit load and adds stiffness to the shipping pallet/load combination. Current pallet design practices often ignore the aspect of load bridging and assume that the pallet payload is flexible and uniformly distributed over the pallet surface. This can influence the load-carrying capacity of the pallet. The study reported in this paper investigated the relationship between the stretch wrap containment force and load bridging in unit loads and the resulting unit-load deflection. The experimental results of this study indicate that an increase in the stretch wrap containment force can improve the unit-load deflection by as much as $81 \%$. The influence of the stretch wrap containment force on pallet deflection is greatest for small packages and pallets with low stiffness. These experimental results provide useful information for realizing more efficient and sustainable unit-load designs.

\section{KEYWORDS}

load bridging, pallet, stress distribution, stretch wrapping, unit load

\section{1 | INTRODUCTION}

The unit load is a general packaging format in the transport and storage of packaged goods in global supply chains. A unit load consists of packages (corrugated boxes, barrels, bottles, etc) on a shipping platform (pallets and slip sheets) that have been secured with load stabilizers (stretch film, shrink film, straps, etc). ${ }^{1}$ In the United States, the most widely used unit load consists of corrugated boxes stacked on a wooden pallet and wrapped with stretch film. ${ }^{2-4}$ The components comprising a unit load mechanically interact with each other during transport and storage, depending on the given supply chain conditions. However, these unit-load components are often designed by different designers with a limited discussion regarding the mechanical interactions among them. This situation can lead to less-efficient unit-load designs and increased material consumption and waste, which adds to the cost and can result in product damage and reduced safety levels. ${ }^{5}$ Investigations into how unitload components mechanically interact is necessary to ensure more sustainable unit-load designs. ${ }^{6}$
Current shipping pallet design practices assume that the payload is flexible and uniformly distributed across the pallet. In reality, most loads are not uniformly distributed because the packages act as a series of discrete loads. Physical interactions between the packages and between the packages and load stabilizers can create additional stiffness in the payload. This leads to the payload bridging across warehouse rack supports. When compared with an actual flexible uniform load, this bridging will reduce the bending moment to which the pallet is exposed. Bridging will reduce unit-load deformation and increase the carrying capacity of the pallet. $^{7}$

The amount of the load bridging can be affected by various characteristics of the unit load such as package size, packaging stiffness, stacking patterns, containment force of load stabilizers, coefficient of friction between boxes, the number of packaging layers, and the pallet stiffness in a unit load. Fegan ${ }^{8}$ and Colie $^{9}$ found that the amount of the load bridging characterized by deflection of the pallet changes for different package stacking patterns and pallet stiffness levels. White et $\mathrm{al}^{10}$ examines the changes in unit-load deflections dependent on different packaging, stacking patterns, and load stabilization 
methods. These findings were later proposed in ISO 8611-3: Pallets for materials handling-Flat pallets-Part 3: Maximum working loads ${ }^{11}$ as a guideline. Recently, Park et $\mathrm{al}^{7}$ also investigated the influence of package size and flute type of corrugated paperboard boxes on load bridging in unit loads and found that an increase in corrugated paperboard box size changed the unit-load deflection, and a change in the flute type of the corrugated paperboard box from B-flute/BC-flute to Eflute reduced the unit-load deflection.

There is a lack of knowledge regarding the influence of stretch wrap containment force on the load bridging on pallets. Containment force is defined as an inward force of the stretch wrap to keep a load together. ${ }^{12}$ The containment force can be affected during stretch wrapping applications by film properties ${ }^{13}$ and wrapping configuration. ${ }^{14}$ For example, heavier gauge film wrapped at higher tension on loads with more weight increases the containment force and leads to more compression and compaction of the load on top of the pallet.

The objective of this study was to experimentally investigate the influence of stretch wrap containment force on load bridging as a function of the package size and pallet stiffness in unit loads under typical warehouse rack storage conditions. The difference in deformation of a simulated pallet will be used to assess the effect.

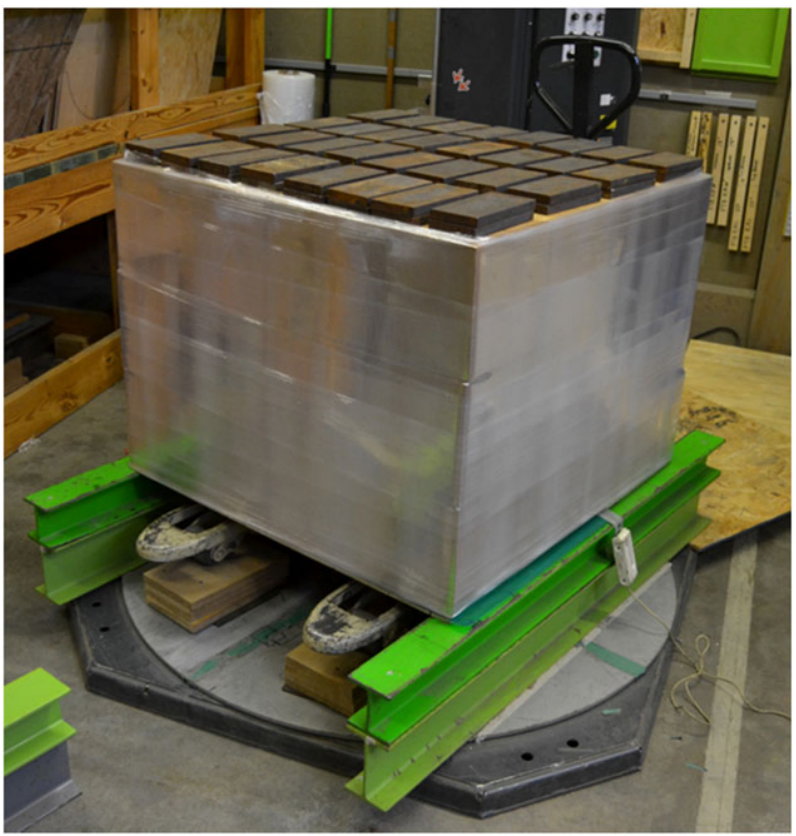

FIGURE 1 Structure of a unit-load sample and the experimental setup used in this study

\section{2 | MATERIALS AND METHODS}

\section{1 | Materials}

The unit-load sample used in this study (Figure 1) consisted of a simulated pallet, 3 layers of packages, and stretch wrap. In addition, 64 metal blocks (30.4 N per metal block) were applied to the top of the unit load to increase the total weight of the unit load. Except for the minor weight variance due to the simulated pallet and stretch wrap types, the total weight of the unit load, including packages $(2560 \mathrm{~N})$ and metal blocks (1930 N), was consistently maintained at $4490 \mathrm{~N}$ throughout the entire experiment. Table 1 shows the detailed characteristics of each component of the unit-load samples used in this study.

\subsection{1 | Simulated pallet segments}

Two birch plywood panels (1016 mm × $1016 \mathrm{~mm}$ ) having different thicknesses were prepared to simulate different pallet stiffness: a 13-mm birch plywood panel and a 19-mm birch plywood panel. The bending stiffness of these panels was measured by 3-point bending tests using a fixed-plate compression tester (Tinius Olsen equipped with four 44 500-N load cells). Park et al ${ }^{7}$ measured 4 different commercial pallet designs to represent the range of pallet stiffness widely used. Adjusting the bending stiffness of the 4 pallets by dividing the stiffness of the pallet by the ratio of the actual width of the pallet and the 1016-mm width of the panel, it was found that the bending stiffness values of these panels were within the range of stiffness of the commercial pallets (Table 2). In this study, the 13-mm birch plywood panel and the 19-mm birch plywood panel were referred to as a low-stiffness simulated pallet and a high-stiffness simulated pallet, respectively.

\subsection{2 | Corrugated boxes}

Three sizes of B-flute-corrugated paperboard boxes were used in this study. The external dimensions of the 3 boxes were $127 \mathrm{~mm} \times 254 \mathrm{~mm} \times 254 \mathrm{~mm}, 254 \mathrm{~mm} \times 254 \mathrm{~mm} \times 254 \mathrm{~mm}$, and $504 \mathrm{~mm} \times 254 \mathrm{~mm} \times 254 \mathrm{~mm}$. The boxes were regular slotted container style boxes. The board combination was a 171/127/171 (g/ $\mathrm{m}^{2}$ ). The value of edge crush test was $5.6 \mathrm{kN} / \mathrm{m}$. The boxes were manufactured and shipped knocked-down by Packaging Corporation of America, Roanoke, Virginia, USA. Rigid oriented strand board (OSB) boxes, manufactured using 13-mm-thick OSB to the exact inside dimensions of the corrugated paperboard boxes, were placed

TABLE 1 List of unit-load components used in this study

\begin{tabular}{|c|c|c|}
\hline Simulated pallet & $\begin{array}{l}\text { Dimension }(\mathrm{L} \times \mathrm{W} \times \mathrm{D}) \\
1016 \mathrm{~mm} \times 1016 \mathrm{~mm} \times 13 \mathrm{~mm} \\
1016 \mathrm{~mm} \times 1016 \mathrm{~mm} \times 19 \mathrm{~mm}\end{array}$ & $\begin{array}{l}\text { Weight } \\
64.7 \mathrm{~N} \\
106 \mathrm{~N}\end{array}$ \\
\hline $\begin{array}{l}\text { Package } \\
\text { (corrugated paperboard box }+ \text { OSB }+ \text { sand })\end{array}$ & $\begin{array}{l}\text { Outer dimension }(\mathrm{L} \times \mathrm{W} \times \mathrm{D}) \\
127 \mathrm{~mm} \times 254 \mathrm{~mm} \times 254 \mathrm{~mm} \\
254 \mathrm{~mm} \times 254 \mathrm{~mm} \times 254 \mathrm{~mm} \\
504 \mathrm{~mm} \times 254 \mathrm{~mm} \times 254 \mathrm{~mm}\end{array}$ & $\begin{array}{l}\text { Weight (filled) } \\
26.5 \mathrm{~N} \\
53 \mathrm{~N} \\
106 \mathrm{~N}\end{array}$ \\
\hline Stretch film & $\begin{array}{l}\text { Dimension }(\mathrm{W} \times \mathrm{T}) \\
508 \mathrm{~mm} \times 0.02 \mathrm{~mm}\end{array}$ & \\
\hline Metal block & $\begin{array}{l}\text { Dimension }(\mathrm{L} \times \mathrm{W} \times \mathrm{T}) \\
203.2 \mathrm{~mm} \times 101.6 \mathrm{~mm}\end{array}$ & $\begin{array}{l}\text { Weight (each) } \\
30.4 \mathrm{~N}\end{array}$ \\
\hline
\end{tabular}


TABLE 2 Description of pallets and simulated pallets investigated in this study

\begin{tabular}{llc} 
Pallets & Dimension $(\mathrm{L} \times \mathrm{W})$ & $\begin{array}{c}\text { Adjusted } \\
\text { bending } \\
\text { stiffness }\end{array}$ \\
\hline $\begin{array}{l}\text { Block class wood pallet } \\
\text { Multiple-use plastic pallet }\end{array}$ & $1209 \mathrm{~mm} \times 1016 \mathrm{~mm}$ & $490 \mathrm{kN} / \mathrm{m}$ \\
\hline $\begin{array}{l}\text { Stringer class wood pallet } \\
\text { Single-use plastic pallet }\end{array}$ & $1209 \mathrm{~mm} \times 1016 \mathrm{~mm} \times 1016 \mathrm{~mm}$ & $265 \mathrm{kN} / \mathrm{m}$ \\
\hline $\begin{array}{l}\text { Simulated pallets } \\
\text { High stiffness (19-mm birch } \\
\text { plywood) }\end{array}$ & $1016 \mathrm{kN} / \mathrm{m}$ \\
\hline $\begin{array}{l}\text { Low stiffness }(13-\mathrm{mm} \text { birch } \\
\text { plywood) }\end{array}$ & $1016 \mathrm{~mm} \times 1016 \mathrm{~mm}$ & $\begin{array}{c}58.8 \mathrm{kN} / \mathrm{m} \\
\text { Bending }\end{array}$ \\
\hline
\end{tabular}

into the boxes. The OSB boxes were then filled with dry sand. Once the OSB boxes were filled with sand, a lid was secured with 4 metal screws to seal the box. Hot glue was applied to each of the flaps of the corrugated paperboard box to seal it. According to ASTM D $4332,{ }^{15}$ the assembled boxes were conditioned at $23^{\circ} \mathrm{C}$ and $50 \%$ relative humidity for at least 72 hours. The weight of each package for the small, medium, and large size packages was 26.5, 53, and $106 \mathrm{~N}$, respectively.

\subsection{3 | Stretch film}

Eighty gauge thickness $(0.02 \mathrm{~mm})$ linear low-density polyethylene stretch film, supplied by Berry Plastics, Evansville, Indiana, USA, was used for stretch wrapping unit-load samples. Three containment force levels were used in this study: 0 (no stretch wrap), 133, and $267 \mathrm{~N}$.

\section{2 | Testing methods}

\subsection{1 | Experimental design and statistical analysis}

Unit-load bending tests using a $3 \times 3 \times 2$ factorial experimental design were performed to investigate the effects of containment forces on unit-load deflection (Table 3). All combinations were tested in triplicate.
A 3-way factorial analysis of variance test was performed to analyse the effects of containment force and package size on the deflection of unit loads on 2 different stiffness levels of simulated pallets. Post hoc analysis was conducted to check the difference among levels of treatments using Tukey honest significant difference method. A statistics software (JMP Pro, Version 10) was used for performing the statistical analysis.

\subsection{2 | Stretch wrapping}

Linear low-density polyethylene stretch film was applied using the stretch wrapping machine. The maximum rotational speed of the turntable was $617 \mathrm{~mm} / \mathrm{s}$ while the speed of the carriage was $30.5 \mathrm{~mm} / \mathrm{s}$ during the stretch wrapping. The stretch film's prestretch was $200 \%$ measured using a film stretch indicator (Highlight, Model PTC919M-HI-10). The wrapping pattern consisted of one bottom wrap and one top wrap with $50 \%$ overlap in the middle. The wrapping pattern was repeated 2 and 4 times to generate 133- and 267-N containment force, respectively. To wrap the unit load with 133 and $267 \mathrm{~N}$ of containment force, overall 227 and $454 \mathrm{~g}$ of the stretch film was applied to the unit load, respectively.

A digital containment force measurement system (Highlight, Model Portable Film Force System) was used to measure the containment force of the stretch wrap. A load cell was located at $457 \mathrm{~mm}$ from the side and $254 \mathrm{~mm}$ from the top of the unit load as described in ASTM 4649-Standard Guide for Selection and Use of Stretch Wrap Films. The precision of the containment force measurement was $\pm 8.89 \mathrm{~N}$ from the target force. The load cell was only used to determine the correct machine settings that results in a 133- or $267-\mathrm{N}$ containment force, and they were removed from the unit load after the containment force measurement was completed. Figure 2 shows the experimental set-up for the containment force measurement.

\subsection{3 | Simulated unit-load bending tests using filled corrugated boxes}

In Figure 3, all unit-load bending tests were conducted on the platform of a stretch wrapping machine (Wulftec, Model WSML-150-b) to

TABLE 3 Experimental design of the unit-load bending test on simulated pallets

\begin{tabular}{|c|c|c|c|}
\hline Stiffness of Simulated Pallet & Containment Force & Package Size $(\mathrm{L} \times \mathbf{W} \times \mathrm{H})$ & Replicates \\
\hline $\begin{array}{l}\text { Low stiffness } \\
\text { (13-mm birch plywood board) }\end{array}$ & $\begin{array}{c}0 \mathrm{~N} \\
\text { (no stretch wrap) } \\
133 \mathrm{~N} \\
267 \mathrm{~N}\end{array}$ & $\begin{array}{l}127 \mathrm{~mm} \times 254 \mathrm{~mm} \times 254 \mathrm{~mm} \\
254 \mathrm{~mm} \times 254 \mathrm{~mm} \times 254 \mathrm{~mm} \\
504 \mathrm{~mm} \times 254 \mathrm{~mm} \times 254 \mathrm{~mm} \\
127 \mathrm{~mm} \times 254 \mathrm{~mm} \times 254 \mathrm{~mm} \\
254 \mathrm{~mm} \times 254 \mathrm{~mm} \times 254 \mathrm{~mm} \\
504 \mathrm{~mm} \times 254 \mathrm{~mm} \times 254 \mathrm{~mm} \\
127 \mathrm{~mm} \times 254 \mathrm{~mm} \times 254 \mathrm{~mm} \\
254 \mathrm{~mm} \times 254 \mathrm{~mm} \times 254 \mathrm{~mm} \\
504 \mathrm{~mm} \times 254 \mathrm{~mm} \times 254 \mathrm{~mm}\end{array}$ & $\begin{array}{l}3 \\
3 \\
3 \\
3 \\
3 \\
3 \\
3 \\
3 \\
3 \\
3\end{array}$ \\
\hline $\begin{array}{l}\text { High stiffness } \\
\text { (19-mm birch plywood board) }\end{array}$ & $\begin{array}{c}0 \mathrm{~N} \\
\text { (no stretch wrap) } \\
133 \mathrm{~N} \\
267 \mathrm{~N}\end{array}$ & $\begin{array}{l}127 \mathrm{~mm} \times 254 \mathrm{~mm} \times 254 \mathrm{~mm} \\
254 \mathrm{~mm} \times 254 \mathrm{~mm} \times 254 \mathrm{~mm} \\
504 \mathrm{~mm} \times 254 \mathrm{~mm} \times 254 \mathrm{~mm} \\
127 \mathrm{~mm} \times 254 \mathrm{~mm} \times 254 \mathrm{~mm} \\
254 \mathrm{~mm} \times 254 \mathrm{~mm} \times 254 \mathrm{~mm} \\
504 \mathrm{~mm} \times 254 \mathrm{~mm} \times 254 \mathrm{~mm} \\
127 \mathrm{~mm} \times 254 \mathrm{~mm} \times 254 \mathrm{~mm} \\
254 \mathrm{~mm} \times 254 \mathrm{~mm} \times 254 \mathrm{~mm} \\
504 \mathrm{~mm} \times 254 \mathrm{~mm} \times 254 \mathrm{~mm}\end{array}$ & $\begin{array}{l}3 \\
3 \\
3 \\
3 \\
3 \\
3 \\
3 \\
3 \\
3\end{array}$ \\
\hline Total runs & & & 54 \\
\hline
\end{tabular}




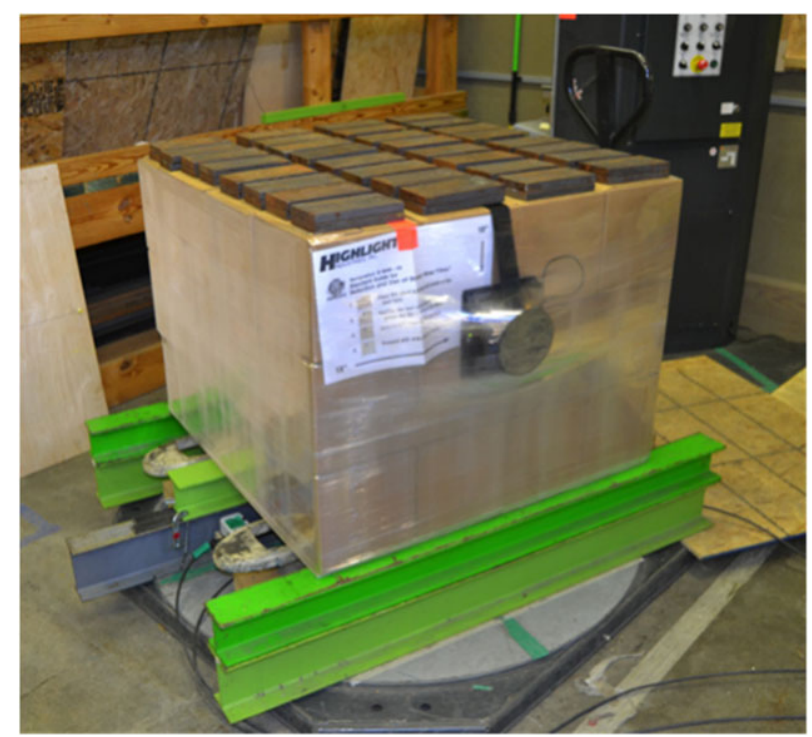

FIGURE 2 Experimental set-up of the containment force measurement using the digital containment fore measurement system

consistently apply the stretch film to the unit load and avoid variations due to the moving of the unit load after preparation. The $1016 \mathrm{~mm} \times 1016 \mathrm{~mm}$ simulated pallet was supported on 2 doublestacked 102-mm-wide and 102-mm-high I-beams with a 914-mm span between the beams. The grain direction of the veneer was perpendicular to the supports. An additional double-stacked 102-mmwide I-beam was positioned with a slight offset from the centre of the simulated pallet to allow the measurement of the deflection of the pallet at the centre of the span and to prevent the deflection of the unit load during the loading and stretch wrapping of the packages. Three layers of packages were placed on the simulated pallet. In addition, 2 layers of metal blocks were stacked on the top layer of the packages to increase the total weight of the unit load. The unit load was stretch wrapped to produce the required containment force.
Following the stretch wrapping of the unit load, 3-string potentiometers (UnitMeasure, Model P510-5-S3) were placed at the front edge, centre, and back edge of the simulated pallet at the centre of the span between the 2 supports. A pallet jack was inserted under the unit load and was used to slightly lift the unit load to remove the third I-beam located next to the centre of the unit load. The unit load was then levelled again relative to the 2 I-beam supports. The pallet jack was lowered to allow the unit load to bend, and the deflections of the unit load were recorded after 30 seconds from lowering the pallet jacks.

\subsection{4 | Pressure distribution mapping}

A digital pressure measurement system, including a pressure pad (Tekscan, Model 5400N-94) and a corresponding sensor map (Tekscan, Model A-M2), was used to measure the pressure distribution between the top of the simulated pallet and the packages during the unit-load bending tests. The Tekscan pressure mat was widely used to characterize the pressure distribution under corrugated boxes during stacked vibration ${ }^{16-18}$ and the pressure distribution under corrugated boxes in a palletized scenario. ${ }^{7,19,20}$ The pressure pad system was connected to a data acquisition software (Tekscan, Model I-Scan) to record the pressure measured by each sensor on the pad from 21 to $103 \mathrm{kpa}$ in real time. The pressure pad was placed between the simulated pallet and the packages, covering a quarter of the simulated pallet surface. The images were taken after the pallet jack was removed.

\subsection{5 | Simulated pallet bending test with rack sup- port condition using an airbag}

Bending tests using a flexible airbag were performed to measure the deflection of the simulated pallets that were supporting uniform flexible load distribution (Figure 4). This represents a nonbridged payload. The simulated pallets were supported on two 102-mm-wide and 102-mm-high I-beams spaced 914-mm apart with a 51-mm underhang

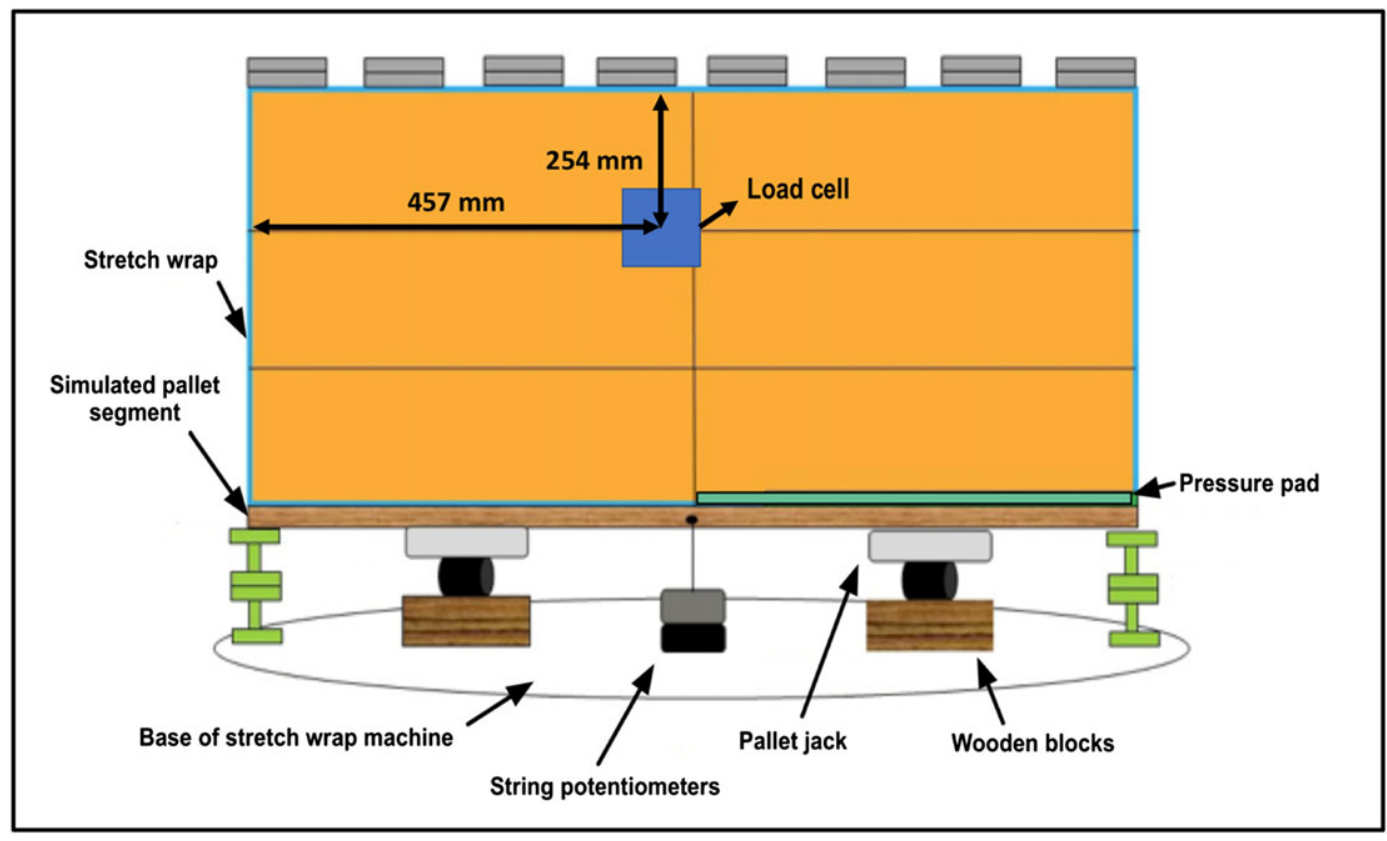

FIGURE 3 Experimental set-up of the unit-load bending test 


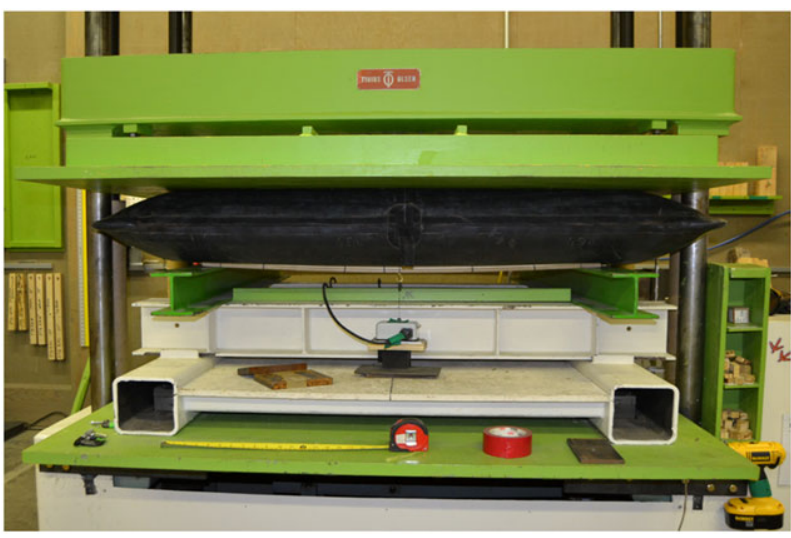

FIGURE 4 Experimental set-up of the simulated pallet bending test with rack support conditions using a flexible airbag to represent a nonbridged payload on top of the pallet

on each side. The simulated pallets were loaded to $4490 \mathrm{~N}$, and the deflection of the simulated pallet was measured after 30 seconds using string potentiometers (UnitMeasure, Model P510-5-S3) placed at the middle of the simulated pallet and at the centre of both unsupported edges of the simulated pallet.

\section{3 | RESULTS AND DISCUSSION}

Table 4 shows the results of unit-load bending tests and simulated pallet bending tests. There were statistically significant effects of the stretch wrap containment force, package size, and the stiffness of the simulated pallet on the unit-load deflection. Differences among the stretch wrap containment force groups for each package size level and simulated pallet stiffness, determined by a post hoc analysis using Tukey honest significant difference tests, are denoted with capital letters in Table 4.

The package size had statistically significant effects on the unitload deflections at all measurement locations, regardless of the levels of the stretch wrap containment force and the stiffness of simulated pallets. The stretch wrap containment force had statistically significant effects on the unit-load deflections at all measurement locations when the unit load was made of the smallest-sized packages (127 mm $\times 254 \mathrm{~mm} \times 254 \mathrm{~mm}$ ) or medium-sized packages (254 mm $\times$ $254 \mathrm{~mm} \times 254 \mathrm{~mm}$ ). However, it did not have a significant effect on the unit-load deflections when the unit load contained the largestsized packages $(504 \mathrm{~mm} \times 254 \mathrm{~mm} \times 254 \mathrm{~mm}$ ). The extremely strong load bridging generated by the largest-sized packages (504 mm $\times 254 \mathrm{~mm} \times 254 \mathrm{~mm}$ ) could be offsetting the effect of stretch wrap containment forces on the unit-load deflection.

Figure 5 shows the fractional changes in the unit-load deflections as a function of the stretch wrap containment force, package size, and stiffness of the simulated pallets. For both the low- and the high-stiffness simulated pallets, the deflections of unit loads decreased as the stretch wrap containment force and package size increased.

The fractional changes in the unit-load deflections due to the stretch wrap containment force increases were larger when the unit load had smaller-sized packages and lower stiffness of pallets. For the low-stiffness simulated pallet, the unit-load deflections measured at the centre with small $(127 \mathrm{~mm} \times 254 \mathrm{~mm} \times 254 \mathrm{~mm})$, medium

TABLE 4 Average unit-load deflections as a function of stretch wrap containment force, package size, and stiffness of the simulated pallets with Tukey honest significant difference results to determine the differences among containment force groups for each package size level and simulated pallet stiffness

\begin{tabular}{|c|c|c|c|c|c|c|c|c|c|c|c|}
\hline \multirow{3}{*}{$\begin{array}{l}\text { Simulated } \\
\text { Pallet } \\
\text { Stiffness }^{\text {a }}\end{array}$} & \multirow{3}{*}{$\begin{array}{l}\text { Package } \\
\text { Size }^{b}\end{array}$} & \multirow{3}{*}{$\begin{array}{l}\text { Containment } \\
\text { Force, } \mathrm{N}^{\mathrm{c}}\end{array}$} & \multicolumn{9}{|c|}{ Average Unit-Load Deflection } \\
\hline & & & \multicolumn{3}{|c|}{ Front Location } & \multicolumn{3}{|c|}{ Centre Location } & \multicolumn{3}{|c|}{ Back Location } \\
\hline & & & $\mathrm{mm}$ & cov, \% & Tukey $^{d}$ & $\mathrm{~mm}$ & cov, \% & Tukey $^{d}$ & $\mathrm{~mm}$ & cov, \% & Tukey $^{\text {d }}$ \\
\hline \multirow{7}{*}{ Low } & \multirow[t]{3}{*}{ Small } & 0 & 38.9 & 4 & A & 4.19 & 5 & A & 38.4 & 6 & A \\
\hline & & 133 & 12.4 & 4 & B & 13.2 & 3 & B & 12.7 & 6 & B \\
\hline & & 267 & 7.6 & 6 & C & 7.9 & 6 & C & 7.6 & 5 & C \\
\hline & Medium & 0 & 15.2 & 10 & A & 16.8 & 8 & A & 15.2 & 10 & A \\
\hline & \multirow[t]{3}{*}{ Large } & 0 & 3.3 & 4 & A & 3.8 & 6 & A & 3.0 & 4 & A \\
\hline & & 133 & 2.5 & 4 & B & 2.8 & 4 & B & 2.5 & 5 & B \\
\hline & & 267 & 2.3 & 3 & B & 2.3 & 3 & C & 2.3 & 4 & B \\
\hline \multirow[t]{5}{*}{ High } & Airbag & & 13.2 & & & 13.5 & & & 14.2 & & \\
\hline & \multirow{2}{*}{ Small } & 0 & 9.9 & 1 & A & 10.7 & 1 & A & 10.4 & 2 & A \\
\hline & & 133 & 5.1 & 3 & B & 5.3 & 3 & B & 5.3 & 2 & B \\
\hline & \multirow{2}{*}{ Large } & 133 & 2.0 & 7 & B & 2.0 & 6 & B & 2.0 & 6 & $A$ \\
\hline & & 267 & 1.8 & 8 & B & 1.8 & 5 & B & 2.0 & 8 & $A$ \\
\hline
\end{tabular}

The low and high stiffness of simulated pallets were made of 13- and 19-mm birch plywood panels, respectively.

${ }^{\mathrm{b}}$ The small, medium, and large sizes of packages have $127 \mathrm{~mm} \times 254 \mathrm{~mm} \times 254 \mathrm{~mm}, 254 \mathrm{~mm} \times 254 \mathrm{~mm} \times 254 \mathrm{~mm}$, and $508 \mathrm{~mm} \times 254 \mathrm{~mm} \times 254 \mathrm{~mm}$, respectively.

${ }^{\mathrm{c}} \mathrm{O} \mathrm{N}$ of containment force means that the unit load had no stretch wrap.

${ }^{\mathrm{d} D i f f e r e n c e s ~ a m o n g ~ c o n t a i n m e n t ~ f o r c e ~ g r o u p s ~ f o r ~ e a c h ~ p a c k a g e ~ s i z e ~ l e v e l ~ a n d ~ s i m u l a t e d ~ p a l l e t ~ s t i f f n e s s ~ a r e ~ d e n o t e d ~ w i t h ~ c a p i t a l ~ l e t t e r s ~(A, ~ B, ~ o r ~ C) ~ d e t e r-~}$ mined by Tukey honest significant difference at $\alpha=0.05$. 


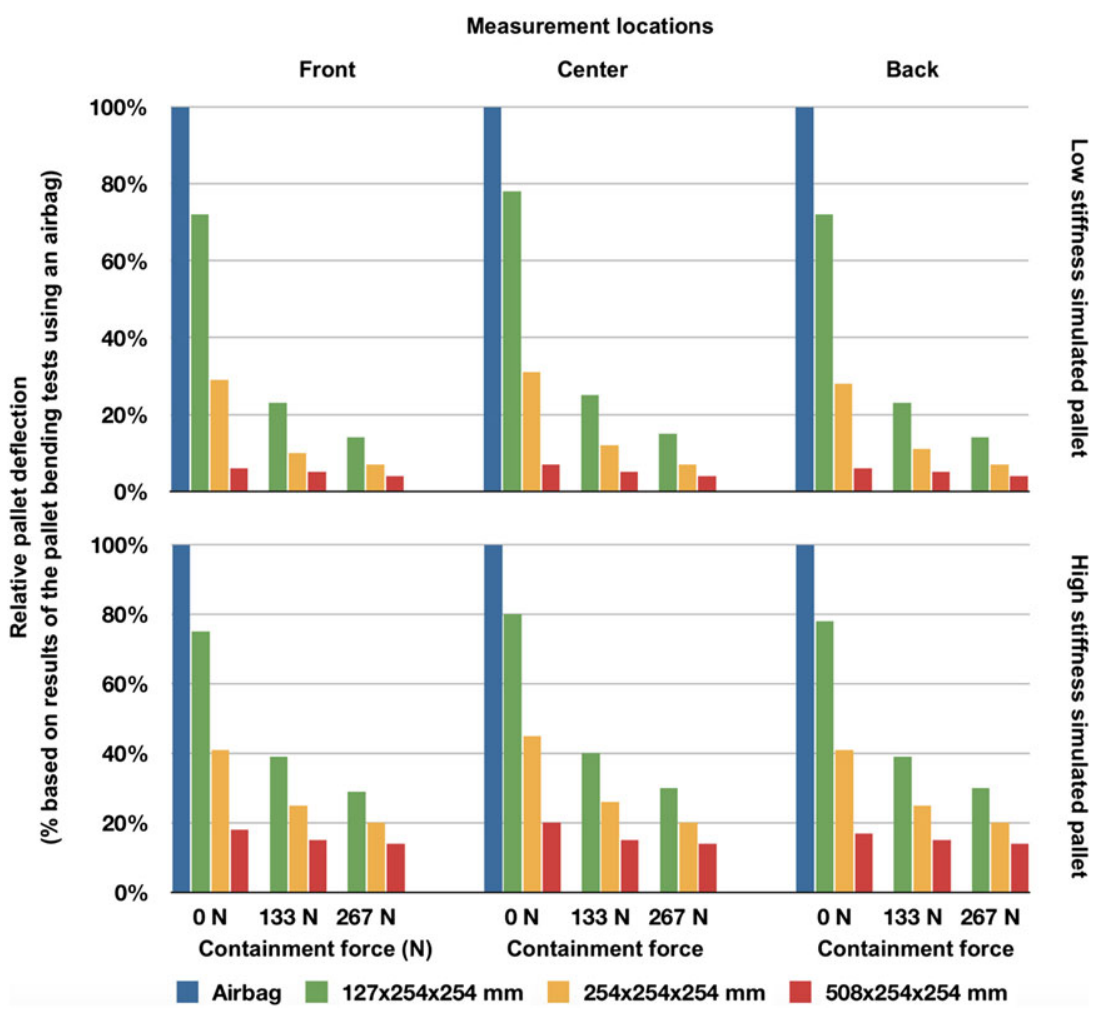

FIGURE 5 Fractional changes in the unitload deflections as a function of the containment force of stretch wrapping, package size, and stiffness of the simulated pallet

(254 mm × $254 \mathrm{~mm} \times 254 \mathrm{~mm})$, and large (508 mm $\times 254 \mathrm{~mm} \times 254 \mathrm{~mm})$ packages were reduced by $68 \%, 63 \%$, and $28 \%$, respectively, when the stretch wrap containment force increased to $133 \mathrm{~N}$ from zero (no stretch wrap). The unit-load deflections were further reduced by $81 \%, 77 \%$, and $44 \%$ when the stretch wrap containment force increased to $267 \mathrm{~N}$ from zero (no stretch wrap). Meanwhile, for the high-stiffness simulated pallet, the deflection of the unit load only decreased by $50 \%, 41 \%$, and $25 \%$, respectively, and by $63 \%, 55 \%$, and $29 \%$, respectively, due to the same changes in containment forces. Similar trends in the unit-load deflections were found in other measurement locations (front and back of the simulated pallets).

The fractional changes in the unit-load deflections due to the package size increases were larger when the unit load had lower stretch wrap containment force and lower stiffness of pallets. For low-stiffness simulated pallets, the unit-load deflections measured at the centre of the unit loads with 0 (no stretch wrap), 133, and $267 \mathrm{~N}$ of stretch wrap containment forces were reduced by $60 \%$, $52 \%$, and $51 \%$, respectively, when the package size increased to medium $(254 \mathrm{~mm} \times 254 \mathrm{~mm} \times 254 \mathrm{~mm})$ from small $(127 \mathrm{~mm} \times 254 \mathrm{~mm} \times 254 \mathrm{~mm})$. The unit-load deflections were further reduced by $91 \%, 79 \%$, and $72 \%$ when the packaging size increased to large $(508 \mathrm{~mm} \times 254 \mathrm{~mm} \times 254 \mathrm{~mm})$ from small (127 mm $\times 254 \mathrm{~mm} \times 254 \mathrm{~mm}$ ). For the high-stiffness simulated pallet, the deflection of unit load decreased by $44 \%, 35 \%$, and $32 \%$, respectively, and by $75 \%, 63 \%$, and $53 \%$, respectively, due to the same changes in the package sizes. Similar trends in the unit-load deflections were found in other measurement locations (front and back of the simulated pallets). Previous studies reported similar results regarding the effects of package size and pallet stiffness ${ }^{7-9}$ on the unit-load deflections. Park et $\mathrm{al}^{7}$ reported that there was a significant reduction in the deflection of the simulated pallet segment as the size of package increased. The studies $^{7-9}$ indicated that the reduction in unit-load deflections due to load-bridging of unit loads became more severe as the stiffness of the pallet decreased.

To investigate deviations from the uniform loading conditions due to the package size changes, the unit-load deflection results with zero stretch wrap containment force (no stretch wrap) were compared with results of the simulated pallet bending tests using an airbag (see Section 2.2.5). For the low-stiffness simulated pallet, the deflections of the uniform loading conditions were reduced by $22 \%, 69 \%$, and 93\%, when the packages were changed to small $(127 \mathrm{~mm} \times$ $254 \mathrm{~mm} \times 254 \mathrm{~mm}$ ), medium (254 mm $\times 254 \mathrm{~mm} \times 254 \mathrm{~mm})$, and large (508 $\mathrm{mm} \times 254 \mathrm{~mm} \times 254 \mathrm{~mm}$ ) boxes, respectively. For the high-stiffness pallet, the deflections decreased by $20 \%, 55 \%$, and $80 \%$, respectively, due to the same changes in the packages.

Changes in the unit-load deflection can be explained by changes in the stress distribution on the simulated pallet due to the characteristics of the unit loads. Figure 6 presents the changes in the stress distribution for the investigated unit loads depending on the containment force, package size, and simulated pallet stiffness. For simulated pallets with both low and high stiffness, more stress was concentrated on the simulated pallet end supported by the rack as the stretch wrap containment force increased. The pressure was mainly concentrated where the box sidewalls touched the top surface of the pallet simulator. When the $127 \times 254 \times 254 \mathrm{~mm}$ boxes were investigated and $0-\mathrm{N}$ containment force was used ( $\mathrm{A}-1$ ), the pressure concentrates under the edges of the 4 boxes evenly distributed across the length of the pallet simulator. In contrast, when the containment force was increased to 133 and $267 \mathrm{~N}$, more pressure was concentrated around the right side of the pictures where the pallet supports were positioned (A-2 and A-3). The pressure that is distributed on the top of the support does not contribute to the 




Each image shows a quarter section of the simulated pallet. The bottom right corner of each image shows the right-front corner of the unit-load supported by the rack. The right side of each image shows the end of the simulated pallet supported by the rack, and the left side of the image shows the middle section of the simulated pallet.

FIGURE 6 Changes in the stress distributions on the top of one quarter of the simulated pallets

bending of the pallet; thus, this pressure redistribution towards the supports could explain the observed reduction in the bending of the pallet under the same loading condition. Increased stress concentration was also observed on the simulated pallet end supported by the rack as the package size increased $(\mathrm{A}-1 \rightarrow \mathrm{B}-1 \rightarrow \mathrm{C}-1)$. The extent of the changes in the stress distribution due to changes in the stretch wrap containment force and package size was more evident on the low-stiffness simulated pallet. The middle section of simulated pallets experienced stress reduction, as more load stress was concentrated on the simulated pallet end supported by the rack due to the changes in the stretch wrap containment force, package size, and simulated pallet stiffness. The decrease of unit-load deflections was caused by the stretch wrap containment force increase, package size increase, and simulated pallet stiffness decrease and was led by the change in stress distribution.
It is hypothesized that the load placed on the top of the pallet was not significant enough to cause sufficient bending of the high-stiffness pallet that would result in an observable pressure redistribution. Therefore, it is important to mention that the load-bridging phenomena only have a significant effect on the bending of the pallet when the load/stiffness ratio of the pallet is sufficiently high to cause significant pallet bending.

In ISO $8611,{ }^{11}$ when the load capacity of the pallet is determined, both the strength and the stiffness of the pallet are taken into consideration. While the stiffness of pallets typically governs the load-carrying capacity of flexible and low-stiffness pallets, the strength of pallets mainly governs the load-carrying capacity of rigid and high-stiffness pallets. Therefore, to be able to determine the effect of increased containment force on the load capacity of a wide variety of pallets, more research need to be done to investigate the influence of these factors on strength of simulated pallets. 


\section{4 | CONCLUSION}

1 Both the stretch wrap containment force and package size significantly affect the deflection of stiffness on all simulated pallets.

2 For the small and medium sizes of packages, increasing the stretch wrap containment force led to significant decrease in unit-load deflection. However, the containment force effect was not significant for the largest-sized packages due to the extremely strong load bridging caused by the packages. The containment force effect was the greatest for the unit load consisting of the smallest-sized packages and the lower-stiffness simulated pallets resulting $68 \%$ and $81 \%$ reduction, when the containment force increased from 0 to 133 and $267 \mathrm{~N}$, respectively.

3 For all stretch wrap containment forces, the unit-load deflections significantly decreased as the package size increased. The package size effect was the greatest for the unit load having the lowest stretch wrap containment force and the lower-stiffness simulated pallet resulting $60 \%$ and $91 \%$ reduction when the package size was changed from the $127 \mathrm{~mm} \times 254 \mathrm{~mm} \times 254 \mathrm{~mm}$ to $254 \mathrm{~mm} \times 254 \mathrm{~mm} \times 254 \mathrm{~mm}$ and $508 \mathrm{~mm} \times 254 \mathrm{~mm} \times 254 \mathrm{~mm}$, respectively. Compared with the deflection results of the uniform flexible loading conditions, the deflection in the unit load decreased $93 \%$ when the unit loads consisted of the largest-sized packages.

4 The changes in stress distribution due to the stretch wrap containment forces and package size increases were more profound when the simulated pallet had a lower stiffness.

5 As the containment force and package size increased, the compression stress decreased at the centre of the simulated pallet and increased at the ends of the simulated pallet. The redistribution of compression stresses correlates with the lower deflection in the unit load when higher stretch wrap containment force and larger-sized packages were applied. The stress concentration at the pallets' edges caused by the stretch wrap containment force and package size changes should be considered to avoid packaging damages during storage in warehouse rack systems.

\section{ACKNOWLEDGEMENTS}

The US Department of Agriculture (USDA) Forest Service, Ongweoweh Corporation, and the members of the Center for Packaging and Unit Load Design of Virginia Tech are all gratefully acknowledged for their financial support of this research project. The Packaging Corporation of America's (PCA) plant in Roanoke, VA, USA, and Highlight Industries are also acknowledged for providing testing material and equipment support for this research project.

\section{ORCID}

Jonghun Park (iD http://orcid.org/0000-0003-3960-017X Laszlo Horvath (i) http://orcid.org/0000-0001-5714-1662 Marshall White (D) http://orcid.org/0000-0003-0777-9814 Robert J. Bush (D) http://orcid.org/0000-0003-2138-9046

\section{REFERENCES}

1. White MS, Hamner P. Pallets move the world: the case for developing system-based designs for unit loads. Forest Prod J. 2005;55:8-16.

2. Twede D, Selke S. Cartons, Crates and Corrugated Board Handbook of Wood and Paper Packaging. Lancaster, PA, USA: DEStech Publications, Inc; 2004.

3. Trebilcock B. Talking pallets with modern readers. Modern Materials Handling. 2013;68:26-34.

4. Rogers LK. Keeping it together. Modern Materials Handling. 2011;66:32-35.

5. White MS. The effect of mechanical interactions between pallets and packaging on packaging costs. Paper and Presentation at the ISTA Dimensions.05 meeting. March 8-11, Orlando, FL, USA. 2005.

6. Park J. Investigation of fundamental relationships to improve the sustainability of unit loads. In Ph. D Dissertation, Department of Sustainable Biomaterials Virginia Tech: Blacksburg, VA, USA, 2015.

7. Park J, Horvath L, White MS, Phanthanousy S, Araman PA, Bush RJ. The influence of package size and flute type of corrugated boxes on load bridging in unit loads. Packag Technol Sci. 2017;30(1-2):33-43.

8. Fegan B. Load support conditions and computerized test apparatus for wood pallets. In M.S. Thesis. Department of Wood Science and Forest Products. Virginia Tech: Blacksburg, VA, USA, 1982.

9. Colie S. Laboratory verification of pallet design procedures. In M.S. Thesis, Department of Wood Science and Forest Products. Virginia Tech: Blacksburg, VA, USA, 1984.

10. White MS, Dibling W, Rupert R, McLeod J. Determination of pallet maximum working loads from nominal load measurements. In: Center for Packaging and Unit Load Design. Blacksburg, VA, USA: VirginiaTech; 1999.

11. ISO. ISO 8611: pallets for materials handling-flat pallets. International Organization for Standardization (ISO): Geneva, Switzerland, 2011.

12. ASTM International. ASTM D4649-03: standard guide for selection and use of stretch wrap films. American Society for Testing and Materials (ASTM) International, West Conshohocken, PA, USA, 2016.

13. Bisha JV. Correlation of the elastic properties of stretch film on unit load containment. In: Ph. D Dissertation, Wood Science and Forest Products. Blacksburg, VA, USA: Virginia Tech; 2012.

14. Singh J, Cernokus E, Saha K, Roy S. The effect of stretch wrap prestretch on unitized load containment. Packag Technol Sci. 2014;27(12):944-961.

15. ASTM International. ASTM D4332: standard practice for conditioning containers, packages, or packaging components for testing. American Society for Testing and Materials (ASTM) International, West Conshohocken, PA, USA, 2014.

16. Jamialhmadi A, Trost T, Ostlung S. A proposed tool to determine dynamic load distribution between corrugated boxes. Packag Technol Sci. 2011;24(6):317-329. https://doi.org/10.1002/pts.936

17. Wang Z-W, Fang K. Dynamic performance of stacked packaging units. Packag Technol Sci. 2016;29(10):491-511. https://doi.org/10.1002/pts.2232

18. Fang K, Wang, Z-W. The statistical characteristics of maxima of contact force in stacked packaging units under random vibration, Packag Technol Sci 2017;31(5);261-276 - Online publication only. https:// doi.org/10.1002/pts.2313

19. Yoo J. Modeling compressive stress distribution at the interface between a pallet deck and distribution packaging. In: Disseratation, Wood Science and Forest Products. Blacksburg, VA, USA: Virginia Tech; 2011.

20. Baker M, Horvath, L, White, MS, Scott, M. Application of beam on elastic foundation to the interaction between a corrugated box and pallet deckboard. Packag Technol Sci 2017;31(5);377-385 - Online publication only.https://doi.org/10.1002/pts.2338

How to cite this article: Park J, Horvath L, White $M$, Araman P, Bush RJ. The influence of stretch wrap containment force on load bridging in unit loads. Packag Technol Sci. 2018;31:701-708. https://doi.org/10.1002/pts.2385 